Int. J. Dev. Biol. 56: 403-406 (2012)

doi: $10.1387 / \mathrm{ijdb} .120020 \mathrm{az}$

\title{
Noggin4 expression during chick embryonic development
}

\author{
ALEXANDER V. BORODULIN\#, FEDOR M. EROSHKIN*, ANDREY V. BAYRAMOV and ANDREY G. ZARAISKY* \\ Shemyakin-Ovchinnikkov Institute of Bioorganic Chemistry, Russian Academy of Sciences, Moscow, Russia
}

\begin{abstract}
We describe here the expression pattern of Noggin4 during the early development of the chick embryo (Gallus gallus). The expression of this gene starts with the onset of gastrulation (stage HH4), in two bilateral bands along the primitive streak, with a local maximum around Hensen's node. By the end of gastrulation, Noggin4 transcripts are distributed diffusely throughout the epiblast, with the highest concentration in the head ectoderm. Interestingly, the expression of Noggin4 during the first half of gastrulation demonstrates a clear left-right asymmetry in Hensen's node, being much more intensive in its right anterior portion. During neurulation, Noggin4 is expressed mainly in the neuroectoderm, with the most intensive expression in the head and lateral neural folds. In mesoderm derivatives, expression is seen in somites but not in the notochord. In general, primarily ectodermal and diffusive expression of Noggin4 in chick embryo, with a maximum in the anterior neurectoderm, resembles that of its ortholog in Xenopus, which indicates a conservative function of this gene in evolution.
\end{abstract}

KEY WORDS: Noggin, Noggin4, chick embryo

During the last several years, at least three sub-families of Noggin genes, including Noggin (Smith and Harland, 1992), Noggin2 (Fletcher et al., 2004) and Noggin4 (Eroshkin et al., 2006), were identified in vertebrates. Among them, proteins of Noggin4 subfamily have primary structures very different from those of Noggin1 and Noggin2. This indicates that molecular functions of Noggin4 could be different from those of other Noggins. In support of this, the Xenopus laevis Noggin4, whose probable homologs were identified recently in planarians and named Noggin-like genes (N/g) (Molina et al., 2009), has demonstrated no ability to induce neurogenesis in the Xenopus laevis embryonic ectoderm (Molina et al., 2011). It should be noted, however, that in contrast to the planarian Nlgs, vertebrates Noggin4 proteins have no long (50-60 amino acids) and quite conservative fragments between their $5^{\text {th }}$ and $6^{\text {th }}$ cysteine residues, the feature that sharply distinguishes planarian Nigs from other Noggin family proteins (Eroshkin et al., 2006; Molina et al., 2009).

Since the expression of Noggin4 was studied hitherto only in one vertebrate species (Xenopus laevis), it would be important to investigate expression of this gene in other organisms, preferably with maximally different type of embryogenesis. Such data could allow one to speculate on conservation or, conversely, variability, of Noggin4 functions during evolution. As no functional orthologs of Noggin4 were found in mammals, we investigate now the expres- sion pattern of Noggin4 in chick (Gallus gallus), a traditional model of developmental biology, with early course of embryogenesis sharply different from amphibian but resembling that of mammals.

\section{Results}

The developmental stages of embryos were defined as described (Hamburger and Hamilton, 1992). The expression pattern of Noggin4 was analyzed by RT-PCR and the whole mount in situ hybridization, beginning from Hamilton-Hamburger stage $1(\mathrm{HH} 1)$ and up to $\mathrm{HH} 12$ stage.

Avery weak expression signal was detected by RT-PCR already at HH1. Signal level gradually increased at later stages (Fig. 1). At the same time, no expression of Noggin4 was revealed anywhere in the embryo by the whole-mount in situhybridization until stage $\mathrm{HH} 4$ (Fig. 2A,B). At this stage, the expression was observed along both sides of the primitive streak (PS), with the highest level of signal in the regions of Hensen's node $(\mathrm{HN})$ and the posterior marginal zone (PMZ) (Fig. 2C). Interestingly, a slight left-right asymmetry of

Abbreviations used in this paper: $\mathrm{F}$, foregut; $\mathrm{HF}$, head fold; $\mathrm{HH}$, a developmental stage as it determined in [HAMBURGER, V. and HAMILTON, H.L. (1992); HN, Hensen's node; HP, head process; NF, neural folds; PMZ, posterior marginal zone; $\mathrm{PN}$, presumptive neuroectoderm; PS, primitive treak; S, somites.

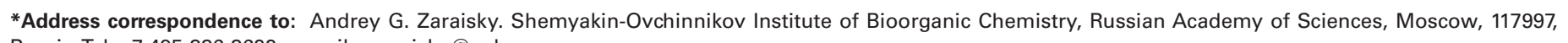
Russia.Tel: +7-495-336-3622. e-mail: azaraisky@yahoo.com

\#Note: These authors have contributed equally to this work. 


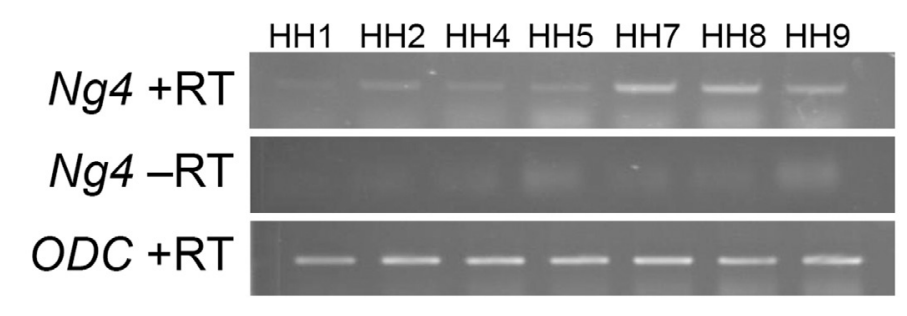

Fig. 1. Noggin 4 PCR with or without reverse transcription $1+R T$ or $-R T$ respectively) of total RNA from embryos at the indicated stages with primers for Noggin 4 and ODC as the loading control.

the expression was detected at stage $\mathrm{HH} 4$ in $\mathrm{HN}$ of some embryos (Fig. 2C'). During $\mathrm{HH} 5-\mathrm{HH}$, this asymmetry can be clearly seen in all embryos (Fig. 2 D',E',F').

In the mesoderm, a weak expression of Noggin4 was observed at stages $\mathrm{HH} 5-\mathrm{HH} 6$ in cells of the head process (HP). However, the expression is disappeared from HP by the time of the head fold (HF) formation at $\mathrm{HH} 6+$ (Fig. 2F). Beginning from this stage, Noggin4 expression is localized primarily in the presumptive neuroectoderm (PN) (Fig. 3A). No expression exceeding the background level was detected at this time in the notochord and in cells of surrounding mesoderm.

At $\mathrm{HH} 7$, the highest expression level was detected in the ectoderm of HF, and in the neural folds (NF) (Fig. 2G). By this stage, a weak expression of Noggin4 can be also seen in the forming first somites, as well as in the un-segmented paraxial mesoderm. Simultaneously, the left-right asymmetry of the expression, which was seen before in $\mathrm{HN}$, is disappeared by this stage (Fig. 2G').

As it may be seen on the transverse sections at the level of NF, the expression in the head region of embryo is localized almost exclusively in the neuroectoderm, rather than the underlying tissues (Fig. 3B). Similar localization of the expression was observed in this region at later stages (Fig. $3 \mathrm{C}$ ). Beginning from this stage, the expression is characterized by a smooth anterior-posterior gradient, having the highest level at the rostral end of the embryonic body axis

Importantly, control hybridization of $\mathrm{HH} 4$ embryos with the sense Noggin4 probe gave no signal at all (Fig. 2J). On the other hand, treatment of embryos with the probe to the homeobox gene Ganf, resulted in the distribution of hybridization signal strongly different from that generated by the anti-sense Noggin4 probe (Fig. 2K). Obviously, both these results confirm specificity of the results obtained with the latter probe.

\section{Discussion}

The expression pattern of Noggin4 in the early development of chick embryo is generally similar to that of its Xenopus laevis homolog (Eroshkin et al., 2006). In particular, in both species, the expression is revealed by the whole-mount in situ hybridization at the comparable stages (from stage $\mathrm{HH} 4$ and 10 in chick and Xenopus, respectively) primarily in PN and later in the neuroectoderm. From the very beginning, the expression is somewhat blur and tends towards wide spreading within the neuroectoderm, forming the anterior to posterior gradient. Moreover, in the mesoderm of both species Noggin4 begins to be intensively expressed only in the forming somites, but no expression of this gene can be seen in the notochord. Thus, all this implies that functions of Noggin4 have been retained in frog as well as chick.

Remarkably, the expression of Noggin4 in early development appeared to be sharply different from that of two other representatives of Noggin family, Noggin1 and Noggin2. In contrast to Noggin4, Noggin1 is expressed during gastrulation exclusively in the presumptive chordamesoderm, and later on, together with Noggin2, in a thin stripe of cells corresponding to the presumptive dorsal forebrain (see Eroshkin et al., 2006 for expression of Noggin1 and 2 in Xenopus laevis and Connolly et al., 1997; Streit and Stern, 1999; Chapman et al., 2002 and GEISHA database, University of Arizona, Tucson, AZ 85724; URL: http://geisha.arizona.edu/

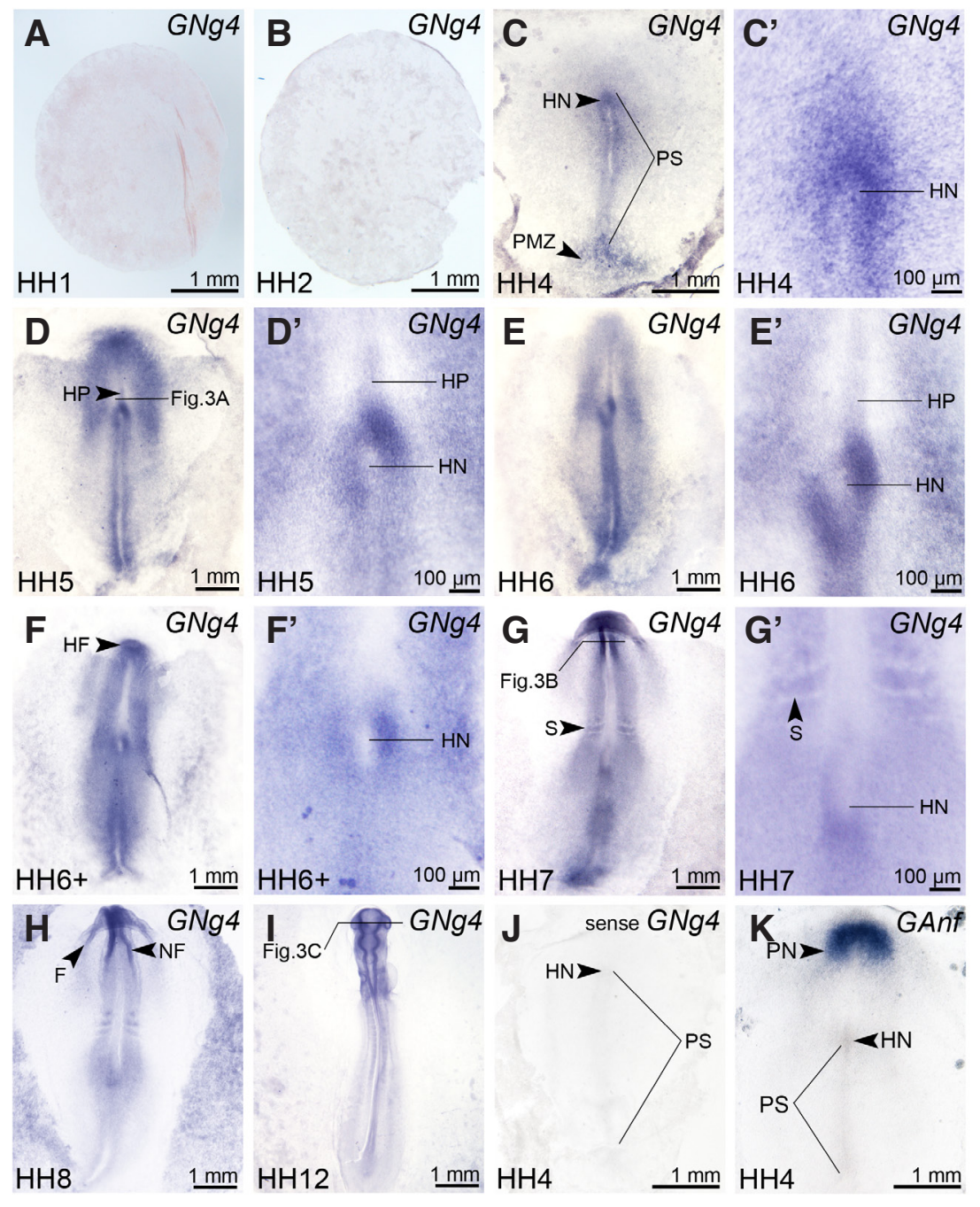

Fig. 2. Expression of Noggin4 in chick embryos at stages HH1-HH12. Enlarged images of Hensen's node region of embryos shown in (C-G) are presented in ( $C^{\prime}-G^{\prime}$.) All embryos are shown from the dorsal side, anterior to the top. Abbreviations: $F$, foregut; HF, head fold; HN, Hensen's node; HP, head process; NF, neural folds; PMZ, posterior marginal zone; PS, primitive streak; $S$, somite. 


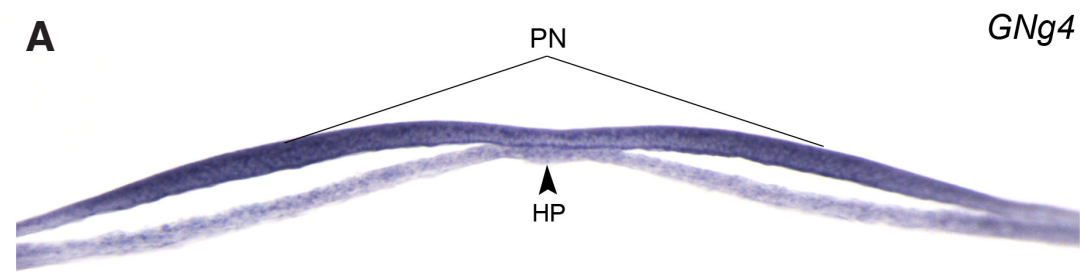

HH5

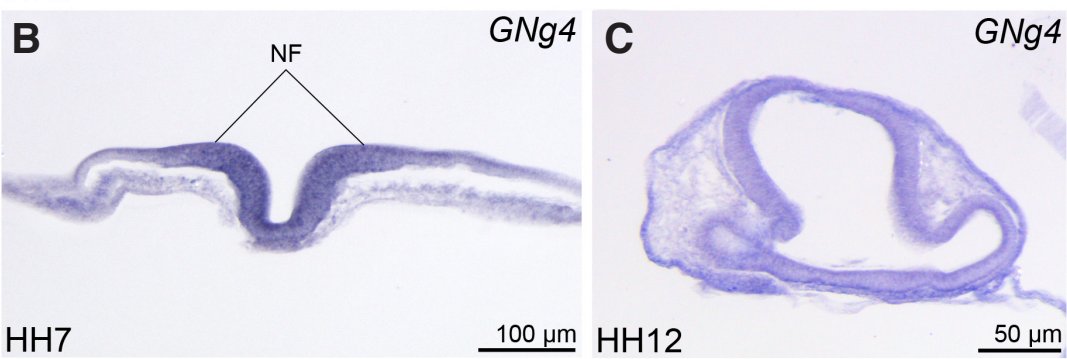

Fig. 3. Histological cross-sections of chick embryos at stages HH5 (A), HH7 (B) and HH12 (C) at the levels indicated in Fig. 2 D, G,I. N, notochord; NF, neural folds; PN, presumptive neuroectoderm. Dorsal side to the top.

geisha/search.jsp?entrez_gene $=459378$ for expression of Noggin 1 in chick). This indicates that physiological, as well as molecular, function of Noggin4 might be also different from those of Noggin1 and Noggin2. In support of this, no ability to inhibit BMP signaling was reported recently for Xenopus laevis Noggin4 (Molina et al., 2011). Instead, the authors of this paper have found out that this protein can slightly ventralize the Xenopus embryo by an unknown mechanism. Given all these, it would be important to test whether Noggin4 retains two other functions recently demonstrated for Noggin1 and Noggin2, namely, the ability to bind and antagonize non-BMP TGFbeta proteins and Wnt (Bayramov et al., 2011).

An intriguing feature of the Noggin4 expression pattern in chicks, which was not reported for Noggin4 in Xenopus, is its asymmetrical expression in HN. Interestingly, the expression of Noggin4 in $\mathrm{HN}$ at $\mathrm{HH} 5$ in chicks corresponds to that of two right-expressing genes - cAct-Rlla (Levin et al., 1995) and MID1 (Granata and Quaderi, 2003). As protein products of the latter two genes are involved in the early patterning along the left-right body axis, one may suppose that Noggin4 may also participate in the process of the left-right asymmetry establishment.

\section{Materials and Methods}

\section{Cloning of Noggin4 cDNA and RT-PCR}

Using the fact that all Nogginfamily genes contain no introns, we obtained the Noggin4 coding sequence by PCR from Gallus gallus genomic DNA with the following primers designed on the base of a sequence deposited in Gene Bank (AY779059):

forward: 5'- GCACCGCTCGCCATGCAGGACCCCT; reverse: 5'- CCCCCTCAGCGGCAGGA. The purified Noggin4 cDNA was cloned into the $P G E M-T$ vector (Promega) and sequenced.

Samples of the total RNA were prepared from the whole embryos at the appropriate stages (5 embryos for each sample) as described (Zaraisky et al., 1992). PCR was performed with the following primers: 5'- GGGATGGAGCTGCCCCCTGA and 5'- CCAGCAGCTTGAGGTGAGCGA. The 25 $P C R$ cycles were made. As the internal control the expression of $O D C$ was monitored in the same samples with primers: 5'-CGGCGGAGGGTTTCGGGGTT and 5'-AGGCCCCGGACCCAGGTTACT for 18 cycles of PCR.

\section{Whole-mount in situ hybridization}

The digoxigenin-UTP-labeled anti-sense and sense RNA probes were synthesized with either T7- or SP6-RNA polymerase (Promega) respectively from DNA fragment obtained from $p G E M-T$-Noggin4 plasmid by PCR with M13-direct and M13-reverse primers. The probe for Ganf mRNA was obtained as described (Kazanskaya et al., 1997). Eggs were collected not later than 3 hours after oviposition. An incubation of the eggs was performed during proper time for embryos to reach certain stage. After incubation, embryos were removed from yolk, washed in PBT (phosphate-buffered saline with $0.1 \%$ Tween-20) and fixed with ice-cold MEMFA fixative (paraformaldehyde 3.7\%, EGTA 2mM, MsSO4 1mM, MOPS 0.1M) at room temperature for two hours. After fixative was removed by washing in PBT, embryos were treated with $50 \%$ and $96 \%$ $\mathrm{EtOH}$ and stored in $96 \% \mathrm{EtOH}$ at $-20^{\circ} \mathrm{C}$ overnight. Embryos were rehydrate through a graded $\mathrm{EtOH}$ series, rinsed triply in PBT and digested in Proteinase $\mathrm{K}(10 \mu \mathrm{l} / \mathrm{ml}) 5$ to $10 \mathrm{mins}$. Digestion was stopped by washing in $0.1 \mathrm{M}$ triethanolamine with $0.1 \%$ acetic anhydride. After that, embryos were rinsed in PBS twice and fixed in MEMFA over 20 mins. Fixative was removed by two washings in PBT, prehybridized in $300 \mu \mathrm{l}$ of prehybridization solution ( $50 \%$ formamide, $5 x$ SSC, Torula RNA $(1 \mathrm{mg} / \mathrm{ml})$, Denhardt's solution, 0.1\% Tween-20, 0.1\% Chaps and 10mM EDTA) over 120 mins. The solution was replaced by $300 \mu \mathrm{l}$ of digoxygenin-labeled RNA probe, and hybridization was performed overnight at $60^{\circ} \mathrm{C}$. After that, embryos were washed by 500 $\mu \mathrm{l}$ of prehyb over 60 mins at $60^{\circ} \mathrm{C}, 2 x \mathrm{SSC}(300 \mathrm{mM} \mathrm{NaCl}, 30 \mathrm{mM}$ sodium citrate) twice each of 60 mins at $60^{\circ} \mathrm{C}, 0.2 \times \mathrm{SSC}$ over 30 mins at $60^{\circ} \mathrm{C}$ and $0.2 \times$ SSC over 30 mins at room temperature. After that, embryos were rinsed twice with MAB (100mM maleic acid, $150 \mathrm{mM} \mathrm{NaCl})$ at room temperature and treated with $2 \%$ blocking reagent in MAB over 60 mins, $20 \%$ heat treated lamb serum in $2 \%$ blocking reagent in MAB over 60 mins and 1:1000 anti-Digoxigenin-AP Fab fragments (Roche cat\# 11093274 910) in $20 \%$ heat treated lamb serum in $2 \%$ blocking reagent in MAB overnight at $4^{\circ} \mathrm{C}$. Antibodies were removed by five washings in MAB at $4^{\circ} \mathrm{C}$, then overnight. After that, embryos were treated with alkaline phosphatase buffer (Chapman et al.) (100mM Tris- $\mathrm{HCl}, 50 \mathrm{mM} \mathrm{MgCl} 2 \cdot 6 \mathrm{H} 2 \mathrm{O}, 100 \mathrm{mM} \mathrm{NaCl}$, $0.1 \%$ Tween-20) containing $2 \mathrm{mM}$ levamisol twice and the color reaction was performed in BM Purple AP Substrate (Roche cat\# 11442074 001) over several days until the desired coloration was reached. After that, embryos were rinsed with AP twice, fixed and stored in MEMFA.

\section{Acnowlegements}

This work was supported by grants from Howard Hughes Medical Institute, RAS program of MCB, Russian Ministry of Education and Science and RFBR to AGZ and AVB and RF President Grants Council to AVB.

\section{References}

BAYRAMOV, A.V., EROSHKIN, F.M., MARTYNOVA, N.Y., ERMAKOVA, G.V., SOLOVIEVA, E.A. and ZARAISKY, A.G. (2011). Novel functions of Noggin proteins: inhibition of Activin/Nodal and Wnt signaling. Development 138: 5345-5356.

CHAPMAN, S.C., SCHUBERT, F.R., SCHOENWOLF, G.C. and LUMSDEN, A. (2002). Analysis of spatial and temporal gene expression patterns in blastula and gastrula stage chick embryos. Dev Biol 245: 187-189.

CONNOLLY, D.J., PATEL,K., and COOKE, J. (1997). Chick noggin is expressed in the organizer and neural plate during axial development, but offers no evidence of involvement in primary axis formation. Int. J. Dev Biol 41: 389-396.

EROSHKIN, F.M., ERMAKOVA, G.V., BAYRAMOV, A.V. and ZARAISKY, A.G. (2006) Multiple noggins in vertebrate genome: cloning and expression of noggin2 and noggin4 in Xenopus laevis. Gene Expr Patterns 6: 180-186.

FLETCHER, R.B., WATSON, A.L. and HARLAND, R.M. (2004). Expression of Xenopus tropicalis noggin1 and noggin2 in early development: two noggin genes in a tetrapod. Gene Expr Patterns 5: 225-230. 
HAMBURGER, V. and HAMILTON, H.L. (1992). A series of normal stages in the development of the chick embryo. 1951. Dev Dyn 195: 231-272.

KAZANSKAYA, O.V., SEVERTZOVA, E.A., BARTH, K.A., ERMAKOVA, G.V., LUKYANOV, S.A., BENYUMOV, A.O., PANNESE, M., BONCINELLI, E., WILSON, S.W. and ZARAISKY, A.G. (1997). Anf: a novel class of vertebrate homeobox genes expressed at the anterior end of the main embryonic axis. Gene 200: 25-34.

LEVIN, M., JOHNSON, R.L., STERN, C.D., KUEHN, M. and TABIN, C. (1995). A molecular pathway determining left-right asymmetry in chick embryogenesis. Cell 82: 803-814.

MOLINA, M.D., NETO, A., MAESO, I., GOMEZ-SKARMETA, J.L., SALO, E. and CEBRIA, F. (2011). Noggin and noggin-like genes control dorsoventral axis regeneration in planarians. Curr Biol 21: 300-305.
MOLINA, M.D., SALO, E. and CEBRIA, F. (2009). Expression pattern of the expanded noggin gene family in the planarian Schmidtea mediterranea. Gene Expr Patterns 9: 246-253

SMITH, W.C. and HARLAND, R.M. (1992). Expression cloning of noggin, a new dorsalizing factor localized to the Spemann organizer in Xenopus embryos. Cell 70: 829-840.

STREIT, A., AND STERN, C.D. (1999). Establishment and maintenance of the border of the neural plate in the chick: involvement of FGF and BMP activity. Mech Dev 82: 51-56.

ZARAISKY, A.G., LUKYANOV, S.A., VASILIEV, O.L., SMIRNOV, Y.V., BELYAVSKY, A.V. and KAZANSKAYA, O.V. (1992). A novel homeobox gene expressed in the anterior neural plate of the Xenopus embryo. Dev Biol 152: 373-382. 


\section{Further Related Reading, published previously in the Int. J. Dev. Biol.}

The zic1 gene is an activator of Wnt signaling

Christa S. Merzdorf and Hazel L. Sive

Int. J. Dev. Biol. (2006) 50: 611-617

Early stages of neural crest ontogeny: formation and regulation of cell delamination

Chaya Kalcheim and Tal Burstyn-Cohen

Int. J. Dev. Biol. (2005) 49: 105-116

X-epilectin: a novel epidermal fucolectin regulated by BMP signalling Karine Massé, Rebecca Baldwin, Mark W. Barnett and Elizabeth A. Jones Int. J. Dev. Biol. (2004) 48: 1119-1129

Acceleration of early chick embryo morphogenesis by insulin is associated with altered expression of embryonic genes Vidya Patwardhan, Madhavi Gokhale and Surendra Ghaskadbi Int. J. Dev. Biol. (2004) 48: 319-326

\section{Evo-Devo of amniote integuments and appendages}

Ping Wu, Lianhai Hou, Maksim Plikus, Michael Hughes, Jeffrey Scehnet, Sanong Suksaweang, Randall Widelitz, Ting-Xin Jiang and ChengMing Chuong

Int. J. Dev. Biol. (2004) 48: 249-270

The biology of feather follicles

Mingke Yu, Zhicao Yue, Ping Wu, Da-Yu Wu, Julie-Ann Mayer, Marcus Medina, Randall B Widelitz, Ting-Xin Jiang and Cheng-Ming Chuong

Int. J. Dev. Biol. (2004) 48: 181-191

The choice between epidermal and neural fate: a matter of calcium Marc Moreau and Catherine Leclerc

Int. J. Dev. Biol. (2004) 48: 75-84

FGF signaling is essential for the early events in the development of the chick nervous system and mesoderm

S Khot and S Ghaskadbi

Int. J. Dev. Biol. (2001) 45: 877-885

Chick noggin is expressed in the organizer and neural plate during axial development, but offers no evidence of involvement in primary axis formation

D J Connolly, K Patel and J Cooke

Int. J. Dev. Biol. (1997) 41: 389-396

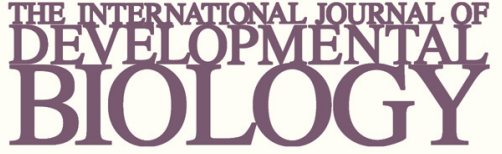

Volume 54 Nos. $6 / 7$ Special Issue
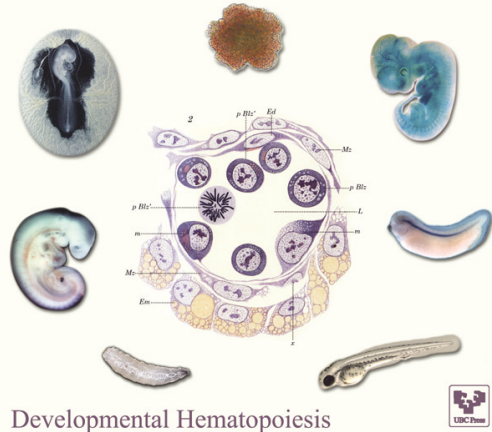

5 yr ISI Impact Factor $(2010)=2.961$

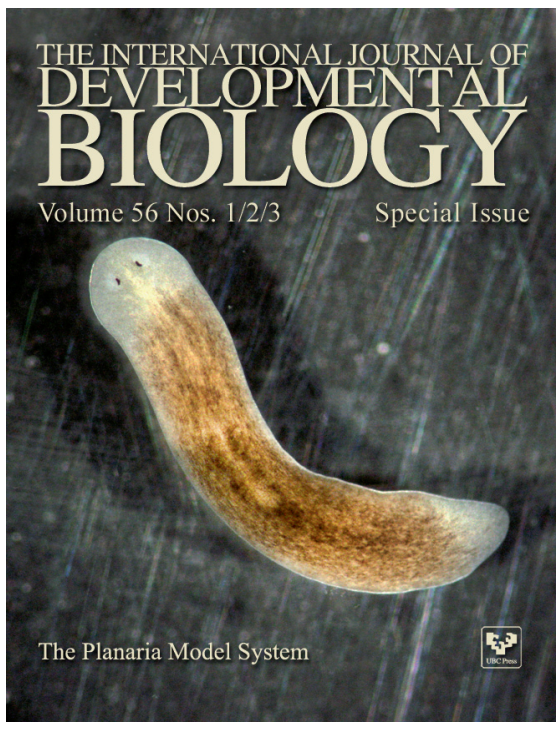

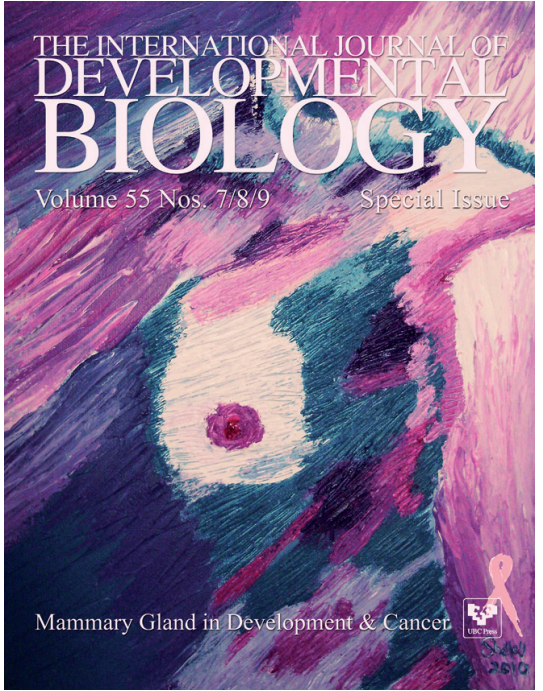

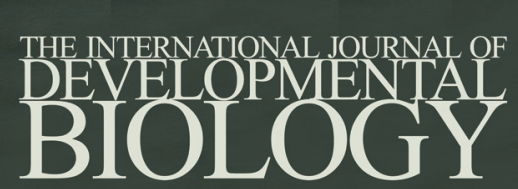

Volume 55 Nos. $4 / 5$

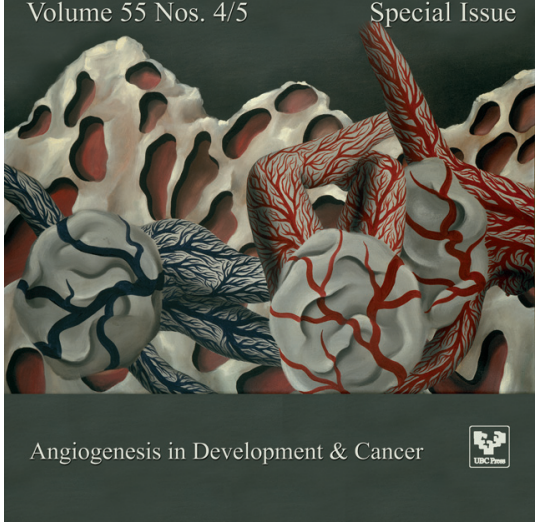

